\title{
The dawn of medical microbiology: germ hunters and the discovery of the cause of cholera
}

In the early history of medical microbiology, investigations into the causes of cholera played an essential role not yet recognized by historians of medicine. The shocking arrival of the 'nineteenth century plague', which had not appeared in Europe prior to the second pandemic in 1830, fuelled the debate on the cause of the disease and the discussion on its contagiousness, galvanizing the research, as has happened in every age for the most feared diseases. Studies and investigations greatly contributed to the displacement of the old 'miasmatic theory', which dominated Western medicine, and to the wide acceptance of the germ theory. This article seeks to fill this gap by describing and interpreting the steps in the transition towards the foundation of modern microbiology and its modern branches.

The first verifiable speculations concerning the role of microscopic life in the process of diseases arose in the early 19th century. In 1836, the civil servant and amateur agronomist Agostino Bassi showed how a disease affecting silkworms could have been caused by a fungus - actually the first micro-organism to be recognized as a contagious agent of an animal disease (Porter, 1973). In 1840, the German anatomist and pathologist Gustav Jacob Henle published the theory that infectious diseases were caused by living microscopic organisms (Churchill, 1989).

The theory of a contagium vivum (germ theory) was only one among many others about the origin of diseases (http://ocp. hul.harvard.edu/contagion/germtheory. html). The older explanation - an imbalance in the four humours of the body - still enjoyed credit. Furthermore, the miasmatic theory suggested that bad air or poisonous vapour filled with particles from decomposed matter (miasmata) was the actual cause of epidemics. This theory was accepted by the majority of the most influential physicians and scientists and was very appealing to British sanitary reformers. In fact, it explained why diseases were epidemic in the crowded, dirty and foul-smelling districts inhabited by the poor, focusing attention on environmental problems rather than on those of individual health and infection.

The arrival of cholera, which ravaged Europe in six major pandemics swept out of India (1817-1823, 1826-1837, 18461862, 1864-1875, 1883-1894 and 18991923) (Rosenberg, 1987), revived the debate about the origin of epidemic diseases and multiplied the attempts to explain the mysterious causes of the new exotic plague that terrified 19th century Europeans because of its seemingly random ravages and its frightening fatality rate (52-55\% in Western Europe) (McNeill, 1976). The question of the contagiousness of the most feared disease at the time divided scientists, physicians and public health officials (Ackerknecht, 1948, 2009). Most of them thought that smallpox, measles and syphilis were contagious, but the opinions were strongly divided on cholera (and also on typhus and typhoid) (Macmichael, 1831). The supporters of the zymotic theory denied contagion presuming that some virus or organism acted in the system like a chemical 'ferment'. The proponents of the germ theory were contagionists and believed that 'the material of contagion' was a living organism, but they were not able to demonstrate its existence and to furnish conclusive experimental proof of cholera's contagiousness (Richmond, 1954).

The most widely accepted opinion was the view of the anti-contagionists, supporters of the miasmatic theory: cholera was a miasmatic disease locally produced, an illness brought about by direct exposure to the noxious emissions of filth and decayed matter. They argued that the disease was not contagious also on the basis of an empirical observation: doctors remained uninfected in spite of treating patients dying of cholera on a daily basis. Moreover, cholera, like yellow fever, was difficult to prove contagious, given the difficulty in reconstructing a chain of transmission during local epidemics (Rosenberg, 1987).

The dominant views hindered the immediate reception of the findings by the British physician John Snow, who was the first to identify certain corpuscles both in contaminated water and in garments of infected humans (Snow, 1849a, b). At the same time, William Budd, later famous for demonstrating that typhoid fever is a waterborne disease, came to the same conclusion by using pathological evidence (Budd, 1849). According to both Snow and Budd, it was spread by water polluted by the bowel evacuations of sick people. According to Budd, the 'cholera poison' was a living organism; meanwhile, by clinically observing the course of the disease, Snow concluded that cholera was caused by some kind of 'germ cell' that multiplied in the body of a sick person. He speculated that cholera could be a communicable disease infecting humans who had swallowed either food or water contaminated by the dejecta of previous cholera victims (Snow, 1855). In the same years, the Italian pathologist Filippo Pacini carried out detailed investigations on the disease. While cholera was devastating Tuscany in 1854, Pacini found the opportunity to carry out several histological examinations of the intestinal mucosa of cholera victims (Bentivoglio \& Pacini, 1995).

His ability to undertake microscopic research was a great help in adapting his own microscope (Fig. 1) for that research, the most modern at that time, which he built with the assistance of Giovanni Battista Amici, an engineer and architect at the University of Bologna who was also a scholar of natural sciences, optics and astronomy (Miniati, 1991). For the 
autopsies he made use of four corpses, from which he examined vomit, blood, watery stools, intestinal fluids and fragments of stomach, and small intestine. Additionally, he made notes on the shedding of the epithelium, and also described the dark and invisible world under the microscope in great detail: 'In the intestinal fluid I found a large number of vibrions which can easily pass unnoticed when they are lost in a certain amount of fluid' (Pacini, 1854). After observing the shape and size of the micro-organisms, his report described that the vibrions were similar to the Bacterium termo of Dujardin (Zvirbulis \& Hatt, 1967), which also had an elongated shape. He paid special attention to this observation in the first three dissections, during which vibrions were very frequently found in human fluids, often in the proximity of the natural orifices of the body.

Nevertheless, while studying the fourth body, he was impressed by the enormous quantity of vibrions that were trapped in the filaments of mucus and endothelial cells: 'Breaking the aggregations of cells and mucus and observing these under the microscope, myriads of vibrions appeared and then disappeared in the fluid and got confused with other floating particles' (Pacini, 1854).

Pacini published his findings in a report (Pacini, 1854), the first of a long series, in which he described the organism, which he called Vibrio cholerae, and its relation to the disease. In conclusion, he stated that cholera was a contagious disease,

characterized by destruction of the intestinal epithelium, followed by extreme loss of water from the blood: for this condition he later recommended the therapeutic intravenous injection of saline solution (Pacini, 1866). However, Pacini, aware that he had no laboratory evidence to demonstrate the relationship between the vibrion and cholera, stated with great honesty that he had not even tried to grow it in pure culture. In fact, 'to attribute the quality of contagion to cholera, it would have been necessary to recognise an unusual species in it that was concomitant in this disease'. This important discovery was completely ignored by the European scientific community, influenced at the time by the localist/contagionist theory of the leading German scientist Max von

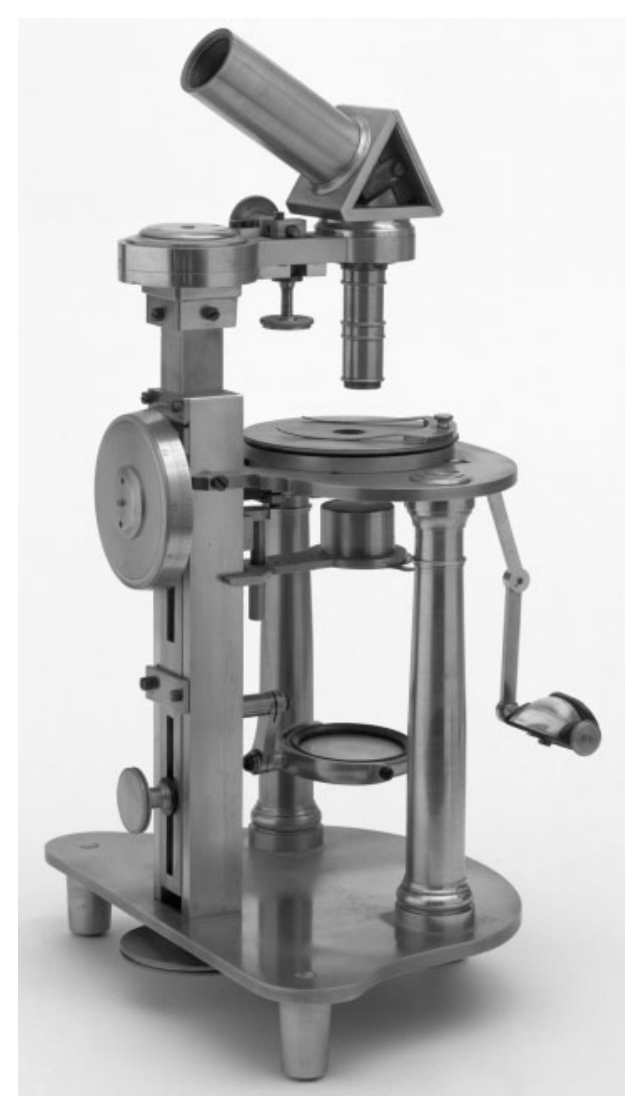

Fig. 1. Compound microscope conceived by Filippo Pacini and manufactured in the workshop of Giovanni Battista Amici (ca. 1845). Material: brass. Size: height, $380 \mathrm{~mm}$; base $226 \times 148 \mathrm{~mm}$. Reproduced with the permission of the Museo Galileo - Istituto e Museo di Storia della Scienza, Florence, Italy. Inv. 3241.

Pettenkoffer, who believed cholera was an airborne disease caused by a combination of three factors: a germ, the local and seasonal conditions and a constitutional predisposition to infection (Locher, 2007).

Despite important advances, the germ theory took hold quite slowly in an era in which the results of the experiments were largely ignored by the medical profession. The beginning of modern microbiology can be traced back to the 1870s: the basis had been developed in the previous decade by the chemist Louis Pasteur. His work on fermentation encouraged the belief that micro-organisms were in the air and could cause human illness (Serafini, 1993). The first step was the evolution from field experiments to systematic laboratory studies of a large range of specific microorganisms using chemistry methods and novel instruments (http://www.brighthub. com/science/genetics/articles/21169.aspx).
The pure-culture technique, based on Pasteur's concept, was perfected by the German scientist Robert Koch (Brock, 1988), who introduced novel techniques and means of cultivating, manipulating and characterizing micro-organisms. Koch was the first to isolate the anthrax bacillus and observe its life cycle, as well as the first to prove that a specific microbe caused a specific disease. Thanks to staining and purification techniques, as well as bacterial growth media including agar plates and Petri dishes (Bridsen, 1994), Koch was able to discover the bacterium causing tuberculosis (Mycobacterium tuberculosis), difficult to cultivate because of its slow growth (Koch, 1884). These findings outlined and paved the way to microbiological research.

In 1883, cholera broke out in Egypt and, fearing its potential introduction into Europe, a new wave of investigation into 
the disease began. As a member of a German government commission, Koch went to Alexandria with a group of German colleagues and students and carried out necropsies on cholera victims. They found a specific bacillus in the walls of the small intestine of victims of cholera but not in victims of other diseases (Howard-Jones, 1984).

According to Koch's report, since this association was quite constant, there could be no doubt that the bacterium was in some way related to the cholera process. Nevertheless, in order to conclude that the bacilli were the cause of cholera, the bacteria needed to be isolated from infected tissues, grown in pure cultures, and the disease reproduced by experimental inoculation to animals. In January 1884, Koch announced that he had successfully isolated the bacillus in pure culture. Then, a few weeks later, he communicated that the bacillus was 'a little bent, like a comma' (Howard-Jones, 1984). Following this, he stated that the organism was constantly found in patients with cholera but never in those with diarrhoea from other causes; additionally, it was rare in the early stages of infection, but was widely present in the characteristic 'rice water stools' of advanced cholera patients. His opponents objected that the causal relationship between the comma bacillus and cholera had not been proved because Koch was not successful in establishing an animal model. It was one of a set of criteria for proof of causation that he would announce in that year and later be known as 'Koch's postulates' (Mazzarello, 2004). That postulate remained undemonstrated until 1959 when the toxin that caused cholera was discovered by Sambhu Nath De (De, 1959).

Koch rapidly realized that the four postulates had severe limitations (Inglis, 2007). Cholera and leprosy could not fulfil all four postulates. Furthermore, $V$. cholerae could be isolated from both sick and healthy people, invalidating postulate 2. Some decades later, in the early era of virology, due to the discovery of viruses as disease-causing agents these limitations would be even more evident.

However, Koch's postulates had great importance in the development of microbiology. They provided a framework for proving the role of microbes in disease. In Pacini's days, no method to establish causality existed. Thirty years after his discovery of $V$. cholerae, Koch independently came to a similar conclusion to the Italian scientist, demonstrating that the comma bacillus was a specific bacterium found exclusively in association with cholera and focusing the diagnostic utility of the bacterium. The germ theory for cholera was finally established, changing minds and eclipsing the old miasmatic theory (Heaman, 1995). Finally, after three decades, the Western medical establishment was prepared to admit that micro-organisms did cause illness. As a consequence of Koch's work (Gradmann, 2009), for which he can rightly be recognized as the founder of medical microbiology, the study of infectious diseases was placed on a stable scientific basis, which finally made control and rational medical treatment possible.

\section{Glossary}

Contagious: Capable of being transmitted by bodily contact with an infected person or object.

Germ theory of disease: States that microorganisms which are too small to be seen except through a microscope can invade the body and cause certain diseases.

Miasmatic theory of disease: An explanation of the origin of epidemics, based on the false notion that they were caused by a miasma, which was considered to be a noxious form of 'bad air' or poisonous vapour or mist that is filled with particles from decomposed matter. This concept was replaced, between about 1850 and 1910 , by the scientifically founded germ theory of disease.

\section{Acknowledgements}

I would like to thank my colleagues for their support in reading this article as well as Tiziana Idini for her help in translating it.

\section{Eugenia Tognotti}

History of Medicine and Human Sciences, Medical School, Department of Biomedical Sciences, Università degli Studi di Sassari, Viale San Pietro 10, 07100 Sassari, Italy
Correspondence: Eugenia Tognotti (tognotti@uniss.it)

Ackerknecht, E. H. (1948). Anticontagionism between 1821 and 1867. Bull Hist Med 22, 562-593.

Ackerknecht, E. H. (2009). Anticontagionism between 1821 and 1867: The Fielding $\mathrm{H}$. Garrison Lecture. Int J Epidemiol 38, 7-21.

Bentivoglio, M. \& Pacini, P. (1995). Filippo Pacini: a determined observer. Brain Res Bull 38, 161-165.

Bridsen, E. (1994). The Development, Manufacture and Control of Microbiological Culture Media. Basingstoke, UK: Oxoid.

Brock, D. T. (1988). Robert Koch: a Life in Medicine and Bacteriology. Berlin: Springer.

Budd, W. (1849). Malignant Cholera: its Mode of Propagation, and its Prevention. London: John Churchill.

Churchill, F. B. (1989). The guts of the matter. Infusoria from Ehrenberg to Bütschli: 18381876. J Hist Biol 22, 189-213.

De, S. N. (1959). Enterotoxicity of bacteria-free culture-filtrate of Vibrio cholerae. Nature 183, 1533-1534.

Gradmann, C. (2009). Laboratory Disease: Robert Koch's Medical Bacteriology. Baltimore: Johns Hopkins University Press.

Heaman, E. A. (1995). The rise and fall of anticontagionism in France. Can Bull Med Hist 12, 3-25.

Howard-Jones, N. (1984). Robert Koch and the cholera vibrio: a centenary. Br Med J (Clin Res Ed) 288, 379-381.

Inglis, T. J. J. (2007). Principia aetiologica: taking causality beyond Koch's postulates. J Med Microbiol 56, 1419-1422.

Koch, R. (1884). Die Aetiologie der Tuberkulose. Mitt Kaiser Gesundh 2, 1-88.

Locher, W. G. (2007). Max von Pettenkofer (1818-1901) as a pioneer of modern hygiene and preventive medicine. Environ Health Prev Med 12, 238-245.

Macmichael, W. (1831). Is the Cholera Spasmodica of India a Contagious Disease? The Question considered in a Letter Addressed to Sir Henry Halford. London: J. Murray.

Mazzarello, P. (2004). The explicative power of the rules: the case of the Koch's postulates. Med Secoli 16, 293-316.

McNeill, W. H. (1976). Plagues and Peoples. New York: Doubleday-Anchor Books.

Miniati, M. (1991). Catalogue of Museo di Storia della Scienza, Firenze.

Pacini, F. (1854). Osservazioni microscopiche e deduzioni patologiche sul cholera asiatico. Gaz Med Ital Toscana 6, 397, 405. 
Pacini, F. (1866). Della Natura del Colera Asiatico: sua Teoria Matematica e sua Comparazione col Colera Europeo e con Altri Profluvi Intestinali. Memoria del Dott. Filippo Pacini. Firenze: Tipografia Uccelli e Zolfanelli.

Porter, J. R. (1973). Agostino Bassi bicentennial (1773-1973). Bacteriol Rev 37, 284-288.

Richmond, P. A. (1954). Some variant theories in opposition to the germ theory of disease. J Hist Med Allied Sci IX 290-303.

Rosenberg, C. E. (1987). The Cholera Years, 2nd edn. Chicago: University of Chicago Press.

Serafini, A. (1993). The Epic History of Biology. New York: Plenum

Press.

Snow, J. (1849a). On the Mode of

Communication of Cholera. London: John Churchill.
Snow, J. (1849b). On the pathology and mode of communication of cholera. Lond Med Gaz 44, 745-752, 923-929.

Snow, J. (1855). Further remarks on the mode of communication of cholera; including some comments on the recent reports on cholera by the General Board of Health. Med Times Gaz 11, 31-35, 84-88.

Zvirbulis, E. \& Hatt, H. D. (1967). Status of the generic name Zoogloea and its species. Int J Syst Bacteriol 17, 11-21. 